\title{
ترجمة القيد في اللغة الفارسية المعاصرة
}

\author{
عبد الحكيم بن فهد السنان \\ برنامج اللغات الحديثة والتزبمة-كلية اللغات والتربمة-جامعة الملك سعود(")
}


القيد عنصر نهوي يحدد دلالة حدث الجملة الفارسية بزمان أو مكان أو كيفية أو شرط أو قسم أو غير ذلك من الظواهر الدلالية التي ترتبط ارتباطاً مباشراً ههذا الحدث الذي هو الفعل، أما موقعه النحوي فيشيع تردده في صدارة هذه الجملة أو في وسطها، أو في آخرها قبل الحدث مباشرة(1).

وقد اجتمع النحويون الإيرانيون على تعريف واحد للقيد وإن اختلف أسلوب طرحهم أو طريقة عرضهم،

يقول ناتل خانلري في كتابه (دستور زبان فارسي) إن القيد هو كلمة أو عبارة تبين كيفية حدوث الفعل (2)؛ ومن ثم فالقيد عنده عنصر يرتبط ارتباطاً مباشر بدلالة بالفعل. وكذلك (حسين عماد افشار) الذي حدد القيد حين ذكر بأنه كلمة أو عبارة أو بجموعة من الكلمات تتدخل في معنى الجملة ومفهومها أو ربما مدلول الفعل فقط (3)، كما أسهم الدكتور (أممد شفائي) في تعريف القيد حين قال إنه كلمة تستخدم لبيان محددات الفعل خصائصه وكيفية وقوعه من حيث المكان والزمان(4).

مما سبق نلحظ أن جميع كتب قواعد اللغة الفارسية لا تختلف كثيراً فيما بينها على تعريف القيد فحسب؛ بل إفا تكاد بتمع على تعريف واحد له.

الملاحظ كما هو واضح من خلال النماذج الثلاثة السابقة أن القيد (هنوز) في المثال الأول يأتي في بداية الجملة وقبل الفاعل، أما في الثانية فيرد موقع القيد (هيج وقت) بين الفاعل ومتمم الفعل، وفي المثال الأخير فنراه يرد قبل الفعل مباشرة للدلالة على كيفية وقوع الحدث.

وكذلك هناك نوع من القيود الفارسية التي تفيد توكيد نفي حدث الجملة، مثل: (أصلاً، هيج؛ بهيج وجه، ...)، رغم أن هذا الحدث منفي بطبيعته، إلا أن الإيراني سواء المتحدث أو الكاتب يرغب في تأكيد دلالة النفي، فيأتي بواحد منها لتحقيق مقصده، ولعل هذه الظاهرة تبدو جلية من خلال النماذج التالية: (أصلاً أو را

$$
\begin{aligned}
& \text { (1) انظر: كروه، مؤلفان، زبان فارسي (2) انتشارات وزارت آموزش ويرورش جاب 1382هـ ش. ص } 145 .
\end{aligned}
$$

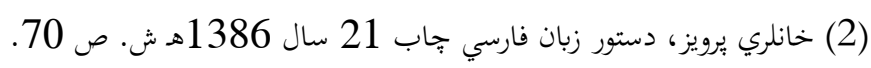

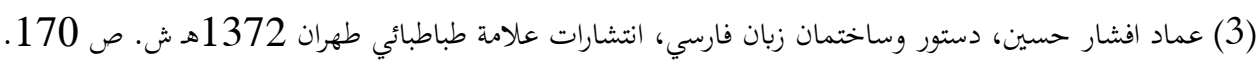

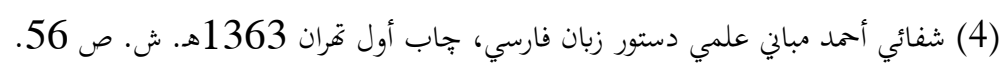


نديدم). المعنى: لم أرهُ أبداً. و(هيج با أو حرف نزدم). المعنى: لم أتحدث معه مطلقاً. و(بيج وجه أو را دوست ندارم) المعنى: لا أحبه على الإطلاق. أما إن كانت الجملة في حالة الاستفهام الاستكاري التي جوابها منفي، فإن الأمر جد مختلف، إذ يكون الفعل مثبتاً وجوابه منفي، على سبيل المثال عندما نقول: (هيج به مكة رفته أي؟ نرفته أم. بمعنى: ألم تذهب إلى مكة مطلقاًٌ لم أذهب. و(هوگز حاضر غائب شنيده أي؟ جوابه نشنيده أم. هل سمعت عن أن الحاضر غائباً? لم أسمع.

هكذا نرى أن السائل عندما توجه في الجملتين السابقتين بسؤال المخاطب، كان يتوقع منه رداً سلبياً، إذ لا يمكن في هذا الموقف اللغوي أن تكون الإجابة مثبتة على الإطلاق.

وهنا بعض القيود التي تضفي على الجملة دلالة الاستفهام، مثل (كجا، كي، جطور، كدام، جند...) كما في الجمل التالية: - n

$$
\begin{aligned}
& \text { - كي مي توانم شما را بينم؟؟ المعنى: متى يمكني أن أراك. }
\end{aligned}
$$

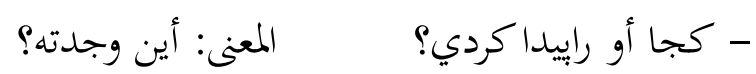

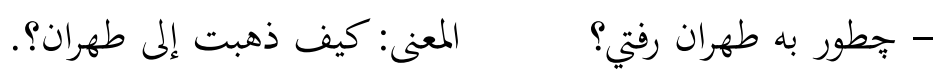

لقد قيدت الكلمات (كي، كجا، جطور) مفهوم الجمل السابقة بسؤال ما، هذا السؤال ربما يكون عن الوقت كما في الأولى منها، أو المكان في الثانية، أو الكيفية في الثالثة، وكأن المرسل يصوغ جملته بكل ما تحويه من عناصر قلت أو كثرت للاستفسار عن وقت أو مكان أو كيفية إتمام حدثها. 


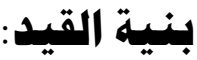

يقسم القيد بشكل عام من حيث البناء إلى ثلاثة أقسام:

1- القيد البسيط: ويطلق هذا النوع على القيود التي تتكون من كلمة واحدة عدا المختصة(1) منها.

أو المشتركة (2) مثل: (اكنون، زير، اندك، كي، جند....)، وذلك على النحو التالي:

- - اكنون محمد در دانشگاه است. المعنى: محمد الآن في الجامعة.

- آن را مي تواني زير ميز بيداكني. المعنى: يمكن أن تجدها تحت الطاولة.

- جند دانشجو در كلاس بودند. المعنى: كان في الفصل بضعة طلاب.

- - آخرين بار كي به مدينة ي منورة رفتي. المعنى: متى ذهبت أخر مرة إلى المدينة المنورة.

2- القيد المركب: يطلق هذا النوع على القيود التي تتكون من كلمتين أو أكثر، مثل (ناكاه، اينجا، سراسر، به

جز، تاكى..)، وترد أنماطها على النحو التالي(3): - - تكرار اسم، مثل: ذره ذره، قطره قطره، گاه كاه...

- تكرار صفت، مثل: كم كم، بـ ش، وكم، اندك اندك...

- - مبهم+ اسم، مثل: هرسو، همه جا، ديخربار م...

- - مر+ اسم، مثل: دردم، درحال، درزمان...

(1) ب ختصة: وهي التي لا تستعمل إلا قيداً.

(2) مشتركة: وهي التي يمكن أن تستخدم قيوداً، ويكن أن تستخدم صفات.

(3) أبو مغلي، عمد وصفي، البسيط في القواعد والنصوص الفارسية، جامعة البصرة، الطبعة الثانية 1987م، ص صـ 157.

خليلي، كامياب، فرهنخ وزاه سازي در زبان فارسي، جاب أول انتشارات قصيدة سرا، سال 1385هـ ش. طهران ص 54. 


$$
\begin{aligned}
& \text { - اين وان+ اسم، مثل: أين قدر، آن وقت، آن گاه.... } \\
& \text { ويرد هذا النوع في الجملة الفارسية هكذا: }
\end{aligned}
$$

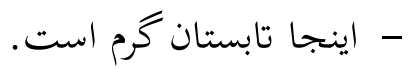

$$
\begin{aligned}
& \text { المعنى: الصيف هنا حار. }
\end{aligned}
$$

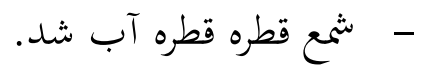

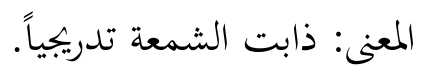

$$
\begin{aligned}
& \text { - مهل جا صحبت از وضع بد اقتصاد است. } \\
& \text { المعنى: الكل يتحدث عن الأوضاع الاقتصادية السيئة. } \\
& \text { - - باصداي انفجار درزمان از خانه خارج شدند. } \\
& \text { المعنى: خرجوا من المنزل فوراً مع صوت الانفجار. }
\end{aligned}
$$

3- القيد المشثق: هو الذي يصاغ من كلمة ولاحقة أو سابقة، بمعنى أنه قد يبنى من اسم ولاحقة، أو سابقة، مثل: (بآساني، شيروار، مردانه، بجا، بيقين، بحقيقة، باشتاب، باتحكم...)، أو من جذر المضارع ولاحقة،

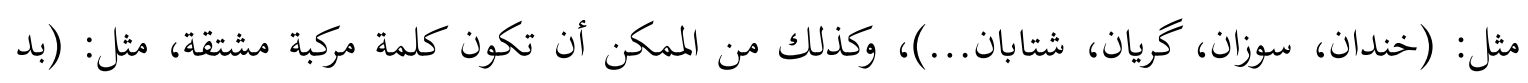
بختانه، به زودي، خوشبختانه، به خوبي، به درستي، هوشمندانه...). وترد مثل هذا القيود في الجملة الفارسية

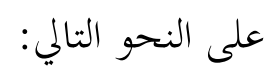
- - ناعاه صداي انفجار مهيب از شمال آمد. المعنى: فجأة جاء من الشمال صوت انفجار مخيف. 


$$
\begin{aligned}
& \text { - - بيقين أو تا شب خواهد آمد. } \\
& \text { المعنى: حتماً سوف يخضر حتى المساء. } \\
& \text { - - - جوانان از كشور مردانه دفاع كردند. } \\
& \text { المعنى: دافع الشباب عن البلاد برجولة. } \\
& \text { - - سعيد خندان كفت. } \\
& \text { المعنى: قال سعيد ضاحكاً. } \\
& \text { - - أو از دانشكاه شتابان بركشت. } \\
& \text { المعنى: عاد من الجامعة مسرعاً. } \\
& \text { - - به زودي أو را خواهي ديد. } \\
& \text { المعنى: ستراه قريباً". - (متر } \\
& \text { - - استاد هوشمندانه به أين سؤال باسخ داد. } \\
& \text { المعنى: أجاب الأستاذ على هذا السؤال بذكاء. }
\end{aligned}
$$

كثيرٌ من القيود لها دور في تكوين الكلمات المركبة الفعلية وغير الفعلية وبنائها، مثل: (هميشه سبز: غُخضرٌ)، (شبخرد: العسة). هاتان الكلمتان اللتان تردان عند الإيرانيين على النحو التالي: (درخت سرو هميشه سبز سمبل جواني است: ريعان الشباب كشجرة السرو المخضرة)، كلمة (هميشه سبز) في هذه الجملة تتكون من (هميشه) قيد، و(سبز) صفة، لتركبت هذه الكلمة وتصبح صفة للشجرة. وفي الجملة: (شبكرد شبها تا صبح بيدار است: العسة يقظة طول الليل حتى الصباح) تتكون كلمة (شبخرد) من (شب) قيد، و(كَرد) جذر المضارع

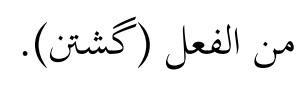




\section{الموقع النحوي للقيد: - الميد}

لبعض القيود دور نخوي خاص في الجملة الفارسية، إذ يؤثر قسم منها في صياغة الفعل، إلى جانب دلالتها بطبيعة الحال، منها: شايد، مخ، لطفا...) ليحولها إلى صيغة المضارع الالتزامي، كما في الجمل التالية: - شايد محمد به مدينة برود. المعنى: من الممكن أن يذهب محمد إلى المدينة المنورة. - ملكر با او صحبت نكردي. المعنى: شريطة أنك لم تكلمه. - (لطفاً آهسته حرف بزنيد. المعنى: من فضلكم تحدثوا بهدوء. والظاهرة الغالبة في اللغة الفارسية أن القيد يرد قبل فعل الجمملة، مثل: - محمد به كلاس آهسته آمد. المعنى: جاء محمد إلى الفصل بهدوء. - ديروز تو دير برگشتي. المعنى: عدت أمس متأخراً. - آها خوب جواب دادند. المعنى: أجابوا ببراعة. - شما سريع مي دويد. المعنى: بترون بسرعة. - دانشجويان از كلاس خشمكين خارج شدند. المعنى: خرج الطلاب من الفصل غاضبين.

وهنالك بعض القيود لها مواقع أخرى غير ملازمتها للفعل، كأن تكون في صدر الجملة، كالقيود الاستفهامية وقيد الزمان والمكان، مثل: (امروز، جند، ديشب، فراد، سال آينده، كي، صبح زود، جقعدر، جطور، كدام، اكنون، حالا...)، كما في الجمل التالية:

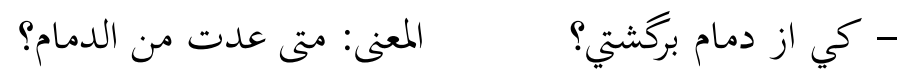

- الآن دوستان شما در لندن هستند. المعنى: أصدقائك الآن في لندن. 
وقد تكون وسط الجملة سواءً كانت (قيد قيد) أو (قيد صفة) التي ترد هكذا: خيلي خوب، بسيار تتد، بسيار داغ، بسيار زشت، خيلي آرام...)، ويككن تصنيفها على النحو التالي: - هند بسيار زود لباس يوشيد(1). المعنى: ارتدت هند ملابسها بسرعة فائقة.

- از خوردن جاي بسيار داغ در سرما لذت مي برم. المعنى: استمتع بشرب الشاي الساخن جداً وقت البرد. وقد يكون القيد الواحد حر الدوران في الجملة، بمعنى أها قد يرد في بدايتها كما سبق أو في وسطها أو في

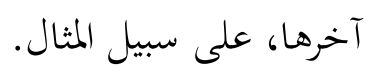

المعنى: تذهب وحدك إلى المدرسة. - فقط تو به مدرسة مي روي. المعنى: تذهب وحدك إلى المدرسة. - تو فقط به مدرسة مي روي. المعنى: تذهب وحدك إلى المدرسة. - تو به مدرسة فقط مي روي. وبالنسبة لقيود الاستثناء فيجب أن ترد قبل المستثنى مباشرة دون الفصل بينهما، هذا النوع الذي يمثله (إلا، جزء، مخصوصاً، غير از،...)، يرد في الجملة الفارسية على النحو التالي: (1) خليلي، كامياب، فرهنگ وازه سازي در زبان فارسي، جاب أول، انتشارات قصيدة سرا سال 1385هـ ش. طهران. ص 133. 
- همه دانشجويان دانشگاه را دوست دارند خخصوصاً سعي. المعنى: جميع الطلاب يهبون الجامعة خاصة سعيد. - ما در كلاس حاضر بوديم به جز خالد. المعنى: الجميع كان حاضراً في الفصل إلا خالد. - همه جا درست شد الا دستشوئي. المتنى: تم إصلاح كل شيء إلا مغسلة اليدين.

\section{د دلالة القيد:}

يعد الدور الدلالي للقيد داخل الجملة دوراً مكملاً، حيث يعطي الجملة مفهوماً خاصاً حسب نوع هذا القيد، سواء كان للتأكيد أو الحالة أو الكمية أو الزمان أو المكان أو الترتيب...، لذي على سبيل المثال لا الحصر

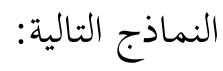
- قيد التأكيد: البته به أو پِاسخ مي دهم. المعنى: طبعاً سأجيب عليه. - قيد الكمية: دانشجويان به كتابخانه زياد مي روند. المعنى: الطلاب يترددون على المكتبة كثيراً. - قيد الحالة: استاد به كلاس بانشاط رفت. المعنى: ذهب الأستاذ إلى الفصل نشيطاً. - قيد الزمان: امروز به كلاس نرفتم. المعنى: اليوم لم أذهب إلى الفصل. - قيد المكان: دانشجويان رو به روى هم نشستند. المعنى: جلس الطلاب مقابل بعضهم بعضاً. 
ويككن للقيد أن يبين أحاسيس المتحدث وشعوره أيضاً عند صياغة الجملة إلى جانب دوره الأساسي؛ حيث إن للقيد دور في إخراج الحالة النفسية للمتحدث كما في: بدبختانه اقتصاد جهان ورشكسته كرديد، التي تعني: من المؤسف أن الاقتصاد العالمي قد اهار، فكلمة (بدجختانه) هي قيد حالة في الأصل قيد مفهوم الجملة بنوع من التخوف والأسف؛ لكنه في هذه الجملة يدل على التأثر الذي حل بكاتبها جراء الهبوط والاهيار الذي حل بالاقتصاد العالمي، ومن ثم رغبته في إيصال هذا الأثر إلى القارئ حتى يتنبه إلى هذه الفاجعة.

\section{إشكالية القيد في الترجمة:}

من المعلوم أن اللغة الفارسية من اللغات الهندوأوروبية التي تتميز بخاصيتها التركيبة، حيث إن لها خصوصية في الصرف والنحو والدلالة تختلف عن اللغات السامية الاشتقاقية، خاصة اللغة العربية، إذ من الغريب أن يتم تداول الكلمات العربية في اللغة الفارسية دون خضوعها لأنظمتها الصوتية والصرفية والدلالية، على سبيل المثال: (كان لم يكن) كما في المثال: تقاضاي شما كان لم يكن أعلام ميخردد، التي تعني: يعلن أنه قد تح رفض طلبك، فنلاحظ أولاً التغيير الجذري في معنى الكلمات العربية الواردة في الجملة، وكذلك التغييرات الصرفية التي حلت بها. وأخيراً التغيرات النحوية كموقع الفعل والفاعل، وعبارة كان لم يكن، التي استبدلت من جملة إلى صفة. والدارس للغة الفارسية لا يخالجه شك في أن نقل الكلمات العربية الأصل التي وردت إلى اللغة الفارسية

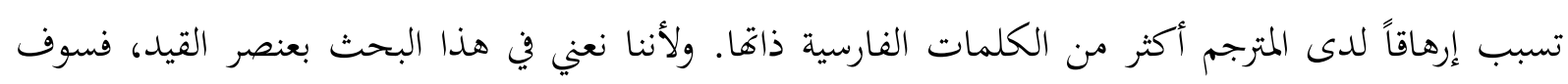
أقصر حديثي عن بعض الإشكاليات التي تواجهنا عند ترجمته إلى لغتنا الأم، مقسماً هذه الإشكاليات إلى قسمين تبعاً للقيد:

\section{أولا: الكامهات العربية المستخدهة قيداً في اللغة الفارسية:} القيود العربية في الفارسية لها ثلاثة أشكال، هي:

ألف) كلمة عربية تستخدم قيداً في الفارسية: أي الكلمات العربية التي دخلت في اللغة الفارسية واستخدمت كقيد. مثل: بلا شك، تدريجاً، بلا ترديد، أحياناً، بدون شك، فقط، كاملاً، نسباً، تقريباً، لطفاً، 
عمداً، أولاً، ثانياً، على الدوام، من بعد، عن قريب، أصلاً، مطلقاً، واقعاً، حقيقتاً، متعاقباً، شفاهاً، اتفاقاً، قهراً، عالماً...) وترد هذه القيود في الجمل الفارسية على النحو التالي: - فقط خواسته ايد به كلامتان عمق بيشترى بدهيد.

$$
\begin{aligned}
& \text { المعنى: أردتم فقط التعمق كثيراً في كلامكم. } \\
& \text { - غالباً از كفته هايش سر در نمي آورد. } \\
& \text { المعنى: غالباً لا يثمن كلامه. } \\
& \text { - مجدداً بازي از سر خرفنه شد. } \\
& \text { المعنى: تم استئناف اللعب مرة أخرى. } \\
& \text { - حتماً شوخي مي كرد. } \\
& \text { المعنى: من المؤكد أنه كان يمزح. } \\
& \text { - با آب تقريباً جوش دوش گرفت. }
\end{aligned}
$$$$
\text { المعنى: استحم بماء ساخن إلى حد ما. }
$$$$
\text { - لطفاً مرا همراهي كنيد. }
$$

المعنى: أرجوك رافقني. 
ب) كلمة عربية يضاف إليها سابقة فارسية (1): أي الكلمة العربية التي رََّّبت معها كلمة فارسية وولدت كلمة واحدة، واستخدمت في الفارسية قيداً ذا معنى، منها: به سرعت، به شدت، بادب، باعقل، به خير، بي عاطفه، بي محبت، باتربيت، بااخلاق،...) وترد في الفارسية هكذا: - أو با عجله به طرف آشيزخانه دويد. المعنى: انطلق نخو المطبخ مسرعاً. - - أين كلام را با تمسخر اداكرد. المعنى: تلفظ هذا الكلام بسخرية. - أما من بي اختيار به تورج فكر مي كردم. المعنى: لكنني كنت أفكر في تورج بلا وعي.

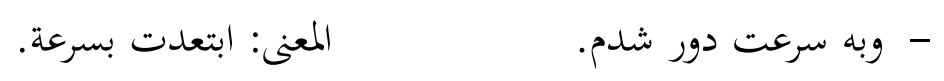

ج) كلمة عربية يضاف إليها لاحقة فارسية (2): هي نوع من الكلمات العربية التي تصاغ معها كلمة فارسية لتصبح كلمة واحدة ذو معنى تستخدم قيداً في الفارسية، من بينها: منصفاته، عاقلانه، غضبناك، خوفناك، وحشتناك، غمناك،...) وترد في بنية الجملة الفارسية كما يلي:

$$
\text { - نمى توانستم قاطعانه تصميم بحيرم) (3). - متاسفانه نتوانسته بودم لرزش صدايم را مخفي كنم. }
$$

(1) السابقة الفارسية: هي مجموعة من الحروف والمقاطع التي تسبق الكلمة لتغير من بنيتها ومعناها، وأحيناناً رتبتها النحوية، مثل: (با، بي، مي، باز،

(2) اللاحقة الفارسية: هي مجموعة من الحروف والمقاطع التي تلحق بالكلمة لتغير من بنيتها ومعناها، وأحياناً رتبتها النحوية، مثل: (أنه، بان، دان، 


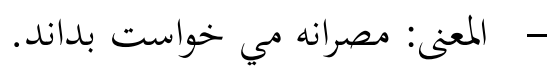

كان يود أن يعرف وبإصرار.

- - متاسفانه قهوه توي خانه نداري) (1) -

المعنى: للأسف لا يوجد لدينا قهوة في المنزل.

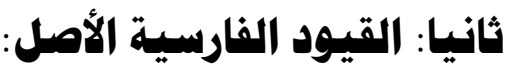

المقصود هنا هو الكلمات التي تستخدم قيوداً في الجملة، سواءً كانت مشتركة أو مختصة. والملاحظ في

هذا النوع من القيود أن الجملة الفارسية الواحدة قد تضمن أكثر من واحد منها. ويمكن تصنيف هذا النوع على

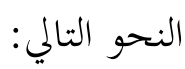

ألف) قيد مشترك: خوب، زيبا، آرام، بلند، تتد فردا، شب، درست، خندان، كريان، شتابان...) وترد

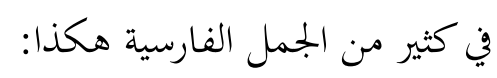
- تو خوب حرف زدي. المعنى: تحدثت جيداً. المعنى: ذهبوا ضاحكين. - آنا خندان رفتند.

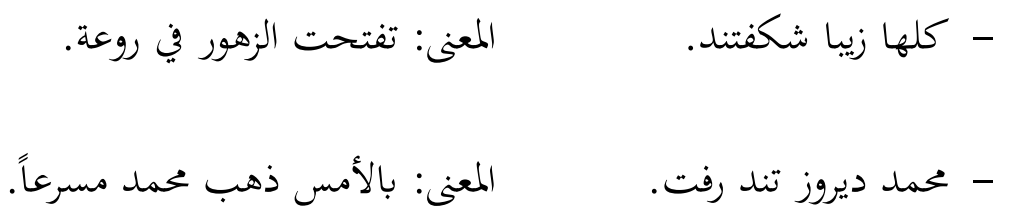

ب) قيد مختص: خيلي، هركز، هيج، هميشه، شايد، هنوز، هند، پِ، آنجا، آنقدر ...)، وترد هكذا:

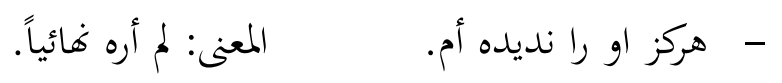
(1) رحيمي فهيمه، باكشت به خوشبختي، جاب 11 سال 1383هـ ش خران ص 153. 
المعنى: لم أتحدث إليه قط.

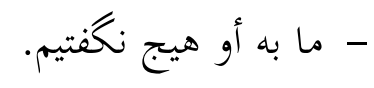

- - بله، اتاق را براي بهرام مي خواهم. المعنى: نعم أريد الغرفة لبهرام.

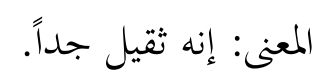

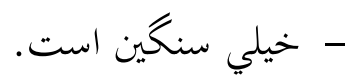

ج) أكثر من قيد واحد في الجملة، وذلك على النحو التالي:

- جند دقيقة به من نغاه كرد. المعنى: نظر إلى بضعة دقائق.

- ديروز خانه خوب تعمير شد. المعنى: شيد بالأمس المنزل بشكل جيد.

- عصر در خيابان باماشين تند مي روم.

المعنى: سأذهب إلى الشارع عصراً بالسيارة مسرعاً.

- فردي آن روز بهرام تنها به خانه بركشت.

المعنى: عاد بهرام وحيداً إلى البيت غداة ذالك اليوم".

- أما برخلاف ديروز خوشبختانه همه أعضاء خانوداه امروز جمع بودند.

المعنى: على خلاف البارحة من حسن الحظ بتمع اليوم جميع أفراد الأسرة.

\section{إشكالية ترجمة القيد:}

لا يرتبط أغلب القيود العربية التي تستخدم في الجمل الفارسية بموقع محدد، كأول الجملة أو آخرها أو

وسطها، لأن ذلك يرجع بطبيعة الحال إلى الكاتب وأسلوبه، وما يريد أن يبلغه للقارئ من معنى، خاصة أن بعض القيود تقبل أن تكون في جميع أجزاء الجملة، أما البعض الآخر فلا يقبل. كذلك يككن أن يكون للقيد مواقع 
مختلفة، دون أن يحدث تغيير للمعنى، وتلك هي المشكلة الحقيقية أمام المترجم، ومن ثم ينبغي له أن يكون ملماً بعض الشيء بحياة الكاتب وأيدلوجيته الأدبية. على سبيل المثال عندما يقول الكاتب (باعجله أو به طرف آشيزخانه دويد، ركض مستعجلاً إلى المطبخ)، وكذلك (او باعجله به طرف آشيزخانه دويد: ركض مستعجلا إلى المطبخ )، وكذلك (أو با عجله به طرف آشيزخانه دويد: ركض إلى المطبخ مستعجلا)، و و(أو به طرف آشيزخانه باعجله دويد: ركض مسرعاً إلى المطبخ)، فإن القيد (باعجله) في الجملة الأولى قد تصدر الجملة لمدف من الكاتب هو بيان السرعة والإنجاز، أما الثانية، فقد كان الهدف منها هو إظهار سرعة فاعل الحدث، ويف الأخيرة كان الهدف منها هو بيان حالة الفعل. ولنا أن نقارن بين دلالة القيد العربي في كل جملتين على النحو التالي:

- في الجملتين (فقط عبد الله مي تواند درس بدهد: عبد الله يمكنه أن يدرس بمفرده) و(عبد الله فقط مي تواند درس بدهد: عبد الله يمكنه أن يدرس فقط)، حيث نرى القيد (فقط) قد تصدر الجملة الأولى ليعطي مدلولاً على أن عبد الله هو الوحيد الذي يدرس. أما في الجملة الثانية فوقع القيد ذاته بعد الفاعل، وأعطى مدلولاً على أن عبد الله لا يمكنه فعل شيء غير التدريس. - وفي الجملتين (نسبتاً در جاي خلوتي نشستيم: إلى حد ما جلسنا قرب المكان الخالي)، و(در جاي نسبتاً خلوتي نشستيم: جلسنا في مكان تقريباً خالياً) نلاحظ أن القيد (نسبتاً) قد تصدر الجملة الأولى لبيان موقع الجلوس، أما في الثانية فهو لبيان عدم ازدحام المكان. 
- وكذلك الجملتان (جداً تو اين لطف را در حق من مي كنى: حقاً ستقدم لي العون)، و(تو أين لطف را در حق من جداً مي كني: أحقاً! ستقدم لي العون)، ورد القيد جداً في مستهل الجملة ليوضح هل هنالك إمكانية لتقديم العون، أما في الجملة الثانية فقد جاء للدلالة على تعجب الكاتب من تقديم العون. ولعلنا نلحظ من خلال النماذج السابقة أن القيد يلعب دوراً مهماً ومحداً في تحديد مفهوم الجملة بشكل عام وفق الموقع الذي يرد فيه، ومن ثم يحتاج المترجم أن يكون حاضر الذهن أثناء التربمة.

كما نجد الظاهرة ذاها تنطبق على القيود الفارسية الأصل التي يشيع استخدامها عند الإيرانين، من حيث الموقع النحوي، والدلالة، لتشكل هي الأخرى صعوبة عند نقلها إلى اللغة العربية. ويبدو ذلك من خلال

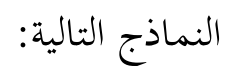

- - (تنها تو مي خواهي به سفر بروي: أنت فقط تريد أن تسافر)، و(تو تنها مي خواهي به سفر بروي: أنت فقط ستسافر)، و(تو مي خواهي تنها به سفر بروي: تريد أن تسافر وحدك فقط)، حيث نلحظ تفاوتاً ملحوظاً في موقع القيد (تنها)، في الجملة الأولى كان الهدف منه بيان أن من يريد السفر هو أنت دون غيرك، وفي أنك لا تريد أن تفعل شيئاً غير السفر، وفي الثالثة أنك لا أن يصحبك أحد أثناء السفر. - (درست مانند بدرر گفت: حقيقي، تحدث مثل أبي)، و(ماند بدرم درست گفت: تحدث بصدق مثل أبي)، في الجملة الأولى كان الغرض بيان أنه تحدث تماماً كأبي، أما الجملة الثانية فكان الهدف بيان أنه تحدث بشكل صحيح كأبي الذي كان كلامه صحيحاً أصلاً. 
- (يي در بي بدرم سيخار مي كشيد)، (يدرم بي در بي سيخار مي كشيد)، و(يدرم سيخار بي در بي مي كشيد: كان أبي يدخن بلا انقطاع). نلحظ أن الجمل الثلاث لم يتغير معناها رغم تغير موقع القيد (بي در

$$
\text { . بي) فيها. }
$$

ونظراً لأن السياق النصي أجدر به إظهار المعنى الحقيقي للقيد الشائع استخدامه بين الإيرانيين، وما يسببه من صعوبات وإنكاليات بالغة لدى الدارسين العرب، لاسيما المقترض منها من اللغة العربية عدة، رأيت أن أدرج نصاً كاملاًكي أضع أمامهم نموذج من الممكن أن يتبعونه في الجانب التطبيقي للغة الفارسية. "ميس سعيدة احتياجي به كلاس زبان نيست. باهمين مدراكي كه داري استخدمت مي كنم. كفتم: حالا كه به دانشگاه نمى روم دوست دارم اتاقم را يا مدارك وخواهينامه هاى آموزشكاهي بركنم. بالأخرة متقاعد شدند ومن باشروع ماه دوم زمستان از شركت مسعود تقاضاي كارم كردم.

در يك روز سرد وبرف زمستان همراه مسعود به شركت زفتم. ساختمان بزرى وزيبابي بود. بناى ساختمان در محوطه ب بزركي واقع شده بود كه أطراف آن را درختان كاج أحاطه مي كردند. برف روي شاخه هاي درختان منظره ي بديعي بوجود آورده بود. مسعود دستش را زير بغلم زد وهر دو با آسانسور به طبقه ي جهارم رفتيم. أو مرا به اتاقش راهنمايي كرد وخفت:

\section{همين جا بنشين تا بر گردم.}

اتاق بزرگي بود با سه ميز جوب گردوبي كه به فاصله ي نسبتاً دوري أز هم قرار خرفته بودند. بر روي يكي از ميزها تلفن وبر روي دو ميز ديكر ماشين تحرير قرار داشت. براه افتادم، وبه طرف بنجره ي بسته رفتم. از آنجا مي توانستم أطراف ساختمان شركت وهمجنين جشم انداز خيابان را بينم. بر اثر ريزش برف حركت 
ماشين ها به كندي انجام مي گرفت، باصداي در برگشتم. مسعود همراه مرد ميانسالي وارد شد. ما به هم معريف شديم و او به من خوشامد كفت. سبس رو به مسعود كرد وخفت:

شما بهتر از هركس مي دانيد كه جون أواخر سال است استخدام ممكن نيست، ايشان مي توانند از همين روز كار خود را شروع كنند، أما استخدام رسمي ايشان به سال جديد موكول خواهد شد. تشكر كردم، واو هم يس از خدا حافظي از در خارج شد. تا نزديك ظهر كنار مسعود بودم، وبا دو همارش آشنا شدم، خانم محسني، زنى سي وينج ساله كله كار تايب لاتين را انجام مي داد وآقاي وكيلي، رئيس كاركزيني شركت. براي صرف ناهار به سلف سرويس رفتيم. ديدن تعداد زيادي افراد خارجي در سلف سرويس مرا به تعجب انداخت. مسعود متوجه حيرت من شدة بود.

\section{وكفت:}

بله، خيلي زيادند وجهه بول هاي كلاني هم به جيب اين بيگانگان مي رود.

خوب اتر فكر مي كنيد وجودشان زائد است جرا عذر شان رانمى خواهيد؟ لبخند تمسخر آميزي زد وكفت: بخاطر يرستيز شركت واينكه بتوانيم روي ٍا بايستيم. ما بايد از وجود اين افراد استفاده كنيم، جون دولت از اين ها حمايت مي كند. تو هنوز جواني واين مسائل را درك نمي كني، ولى اين را بدان، هستند جواناني كه خيلي بيشتر از اين يانكي ها استحقاق استخدام شدن دارند. لب زيرينش را به دندان گزيد وشروع به خوردن دسر كرد. من بانظر مسعود مخالف بودم، زيرا در دل آنان را بر تر از خود مي دانستم. فرداي آن روز بشت ميز كار نشستم. إحساس استقلال مر كردم، حس مي كردم براي خودم كسى شده ام. بر ادرم روبرويم مشغول كار 
بود وبا لبخند كه گاه وبي گاه نثار من دلخرمم مي نمود. أولين حقوقم، بآنكه زياد نبود، خيلي خوشحالم كرد، بطوري كه جندين بار اسكناس ها را شمردم. مسعود دستي به روى شانه ام زد وباخنده گفت: اسكناس ها بانكي است مطمئن باش. كفتم: مي دانم، أما ذوق زده شده أم.

ترجمة النص: ياست سعيدة لا داعي لمذه الدورة سأوظفك بشهاداتك التي تملكينها قلت:

لأنني لم أكمل المرحلة الجامعية سوف أملئ غرفتي شهادات ووثائق تدريبية عوضاً عن الشهادة الجامعة، اقتنعوا أخيراً ومع بداية الشهر الثاني من فصل الشتاء قدمت بطلب وظيفة في شركة مسعود.

في أحد الأيام الباردة الثلجية من الشتاء، ذهبت إلى الشركة مع أخي مسعود كان مبنى كبيراً وضخماً وجميلاً مبنى العمارة كان يقع في ساحة كبيرة التي تحاصرها أشجار الصنوبر وأغصان الشجر تغطيه الثلوج كان منظراً بديعياً. وضع مسعود يده في حضني وصعدنا إلى الطابق الرابع بالمصعد، أرشدني إلى غرفته وقال: اجلسي هناء حتى ارجع كانت غرفته واسعة فيها ثلاث طاولات من خشب شجر الجوز التي كانت تفصلهم مسافات بينهم، على أحد الطاولات يوجد هاتفاً وعلى الأخريات آلة كاتبة. مشيت وقصدت جهة النافذة المغلقة التي كانت تطل على محيط الشركة ومنظر الشارع أيضاً، كانت حركة الشارع بطيئة جداً بسبب 
هطول الثلوج التفت مع صوت صفير الباب وإذا هو دخول مسعود ومعه رجلاً في عمره تعرفنا على بعض ورحب

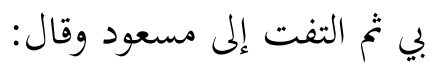

أنت تعلم أكثر من الجميع أننا في ذاية العام والتوظيف في مثل هذا الوقت غير ممكن، ولكن هي تستطيع أن تباشر عملها من اليوم لكن تعينها رسمياً يؤجل إلى السنة الجديد. شكرته خرجنا من الغرفة وذهبت مع مسعود لأتعرف على زملائه الاثنين السيدة محسني امرأة في الخامس والثلاثين تقوم بالكتابة الاتينية على الآلة الكاتبة، والسيد وكيلي رئيس إدارة شؤون العاملين في الشركة، وفي وقت الظهر ذهبنا لصالة الطعام لنتناول الغداء وهو على شكل بوفيه مفتوح كل يخدم نفسه، أدهشني رؤية عدد كبير من الأجانب في البوفيه، لاحظ مسعود دهشتي وقال:

نعم فهم كثيرون ومرتباقم كبيرة، حسناً لو ترون إفم كثر لماذا لا تطلبون منهم الرحيل ابتسم مستهزئاً وقال:

من أجل الحفاظ على مكانة الشركة وحتى نتمكن من الاعتماد على أنفسنا علينا أن نستفيد من تواجد هؤلاء الأفراد، ولأن الحكومة تقوم بحمايتهم، أنتي لازالتِ شابة ولا تستوعبين هذه الأمور لكن أعلمي أن هنالك شباب يستحقون بمرتباهم أن ينالوا الوظيفة بدلا منهم. عض شفاه السفلى وبداء يتناول الحلوى، كنت أخالف رأي مسعود لأنه في قراره نفسي اعتبرهم أفضل مني.

غداة ذلك اليوم كنت جالسة على مكتبي وأشعر بأني مستقلة شعرة أنه قد أصبح لي شأن ومكانة، أخي كان منشغلاً بعمله في جهتي المقابلة وكان يشجعني بابتسامته من حين لآخر. 
أول راتب لي أفرحني كثيراً رغم أنه لم يكن كثيراً حيث قمت بعد الأوراق النقدية عدة مرات، إلى درجة أن مسعود ضرب على كتفي بيده وقال ضاحكاً الأوراق النقدية صحيحة تأكدي قلت:

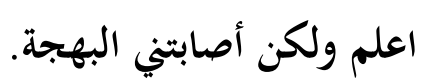




\section{هراجع البحث}

\section{أولا: مراجع عربية: - n}

1- أبو مغلي الدكتور محمد وصفي، البسيط في القواعد والنصوص الفارسية، جامعة البصرة، الطبعة الثانية

2- جمعه، الدكتور بديع محمد، قواعد اللغة الفارسية مع التطبيقات والنصوص.

3- حسن، الدكتور حمدي إبراهيم، قواعد اللغة الفارسية، الجزء الثاني، جامعة الملك سعود، الرياض 1423هـ.

4- باطني، محمد رضا، توصيف ساختمان دستوري زبان فارسي، مؤسسة انتشارات أمير كبير طهران 1385هـ

ش.

5- خانلري يرويز، دستور زبان فارسي §اب 21 سال 1386هـ ش.

6- خليلي، كامياب، فرهنگ وزاه سازي در زبان فارسي-جاب أول انتشارات قصيدة سرا، سال 1385هـ

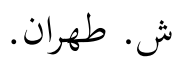

7- خورشيدورد، خسرو، دستور مفصل امروز، انتشارات سخن، طهران، جاب دوم 1383هـ ش.

8- رحيمي فهيمه، باكشت به خوشبختي، جاب يازدهم انتشارات جكاوى 11 سال 1383ه. ش قران. 9- شفائي، أحمد مباني علمي دستور زبان فارسي، خاب أول تران 1363هـ ش. 
10- شريعت محمد جواد، دستور ساده زبان فارسي همراه با بززيه وتركيب، تران، انتشارات أساطير، جاب أول

$$
\text { 1376هـ ش. }
$$

11 - عماد افشار، حسين، دستور وساختمان زبان فارسي، انتشارات علامة طباطبائي طهران 1372هـ ش.

$$
\begin{aligned}
& \text { ص. } \\
& \text { 12- گروه مؤلفان، زبان فارسي (2) انتشارات وزارت آموزش ويرورش خاب 1382هـ. ش. } \\
& \text { 13- مرزبان راد، علي، دستور سودمند، عران: انتشارات بهشتي، جاب هفتم 1370هـ ش. } \\
& \text { 14- مشكوه الديني، د مهدي، دستور زبان فارسي جاب دوم سال 1386هـ ش. دانشگاه فردوسي مشهد. }
\end{aligned}
$$

